\title{
Psicodinâmica Interativa Mãe-Criança e Desmame ${ }^{1}$
}

\author{
Marisa Amorim Sampaio ${ }^{2}$ \\ Ana Rodrigues Falbo \\ Instituto de Medicina Integral Prof. Fernando Figueira \\ Maria do Carmo Camarotti \\ Faculdade de Ciências Médicas da Paraíba \\ Maria Gorete Lucena de Vasconcelos \\ Universidade Federal de Pernambuco \\ Andréa Echeverria \\ Geisy Lima \\ Instituto de Medicina Integral Prof. Fernando Figueira \\ Maria Regina Pereira Ramos \\ Hospital Getúlio Vargas \\ Janaína Viana Zoby do Prado \\ Instituto de Medicina Integral Prof. Fernando Figueira
}

\begin{abstract}
RESUMO - A amamentação representa uma das principais intervenções na redução da morbimortalidade infantil, processo privilegiado à subjetivação, desenvolvimento infantil e prevenção de perturbações no vínculo mãe-filho, quando bem vivenciada pela díade. O estudo analisou a psicodinâmica envolvida no desmame precoce e no desmame tardio, baseado na interação de duas díades mãe-criança com desnutrição grave primária, com bebês entre seis e 15 meses de idade, internadas num hospital escola. Foi utilizado o método qualitativo referenciado na psicanálise, com entrevistas semi-estruturadas e observações. $\mathrm{O}$ desmame precoce pareceu associado à dificuldade de construção da maternidade e vínculo; o desmame tardio refletiu o excesso psicoafetivo materno/dificuldade na entrada do pai.
\end{abstract}

Palavras-chave: aleitamento materno; desmame; relações mãe-filho; desnutrição protéica; psicanálise; pesquisa qualitativa.

\section{Mother-Child Interactive Psychodynamics and Weaning}

\begin{abstract}
Breastfeeding is one of the main interventions in reducing child morbimortality, a privileged process to subjectivation, to child development and to prevention of disturbances in child-mother bond, when it is well experienced by the dyad. The study analyzed the psychodynamics involved in early weaning and late weaning, based on the interaction of two mother-child dyads with severe malnutrition, involving babies aged six and 15 months, hospitalized in a teaching institution. Qualitative methods based on psychoanalysis were used, with semi-structured interviews and observations. Early weaning seemed related to difficulties constructing motherhood and bonding; late weaning appeared to reflect an excess of maternal affection or difficulty in accepting the father figure.
\end{abstract}

Keywords: breast feeding; weaning; mother-child relations; protein malnutrition; psychoanalysis; qualitative research.

A amamentação representa uma das principais intervenções na redução da mortalidade infantil (Toma \& Rea, 2008), fundamental à subjetivação, exercendo papel na prevenção de perturbações no vínculo mãe-filho e no desenvolvimento infantil, quando bem vivenciada pela mãe/díade (Queiroz, 2005; Sales, 2005; Santos \& cols., 2001; Freitas, 2005).

É vasta a produção científica a respeito da amamentação. São abordados os benefícios à criança, à mulher-mãe e à família (Toma \& Rea, 2008), bem como às instituições

1 O trabalho foi derivado de dissertação de mestrado em Saúde Materno Infantil realizado no Instituto de Medicina Integral Prof. Fernando Figueira - IMIP (2008), apoiado por Bolsa da Coordenação de Aperfeiçoamento de Pessoal de Nível Superior (CAPES). Destacamos a colaboração da equipe de saúde (médicos, enfermeiros, técnicos de enfermagem, burocratas) responsável pela Enfermaria "E" do IMIP.

2 Endereço para correspondência: Rua dos Coelhos, 300, Boa Vista, Recife, PE. CEP 50070-550. Telefone: (81) 2122-4702 (Diretoria de Pesquisa).E-mail: marisasampaio@hotmail.com hospitalares (Santos \& cols., 2001) e ao Estado (Almeida \& Novak, 2004). No entanto, é escassa a publicação sobre os benefícios ao par mãe-criança, principalmente os trabalhos de metodologia qualitativa referenciados na psicanálise.

O reconhecimento da importância da amamentação motiva o estudo dos fatores associados à sua duração $(\mathrm{Li}$, Fein, Chen \& Grummer-Strawn, 2008), destacando-se os sociodemográficos e econômico-culturais (Carrascoza, Costa Junior \& Moraes, 2005; Faleiros, Trezza \& Carandina, 2006; Vasconcelos, Lira \& Lima, 2006; Chaves, Lamounier \& César, 2007), psicológicos (O’brien, Buikstra \& Hegney, 2008), a falta de consciência das mães sobre as vantagens da amamentação e o despreparo dos profissionais de saúde para orientá-las acerca dessas vantagens (Almeida \& Novak, 2004; Ramos \& Almeida, 2003).

$\mathrm{O}$ incentivo ao aleitamento materno representa uma das principais ações em saúde. A despeito dos seus benefícios, bem como das várias e constantes iniciativas para estimular e apoiar sua duração, as taxas de aleitamento materno no 
Brasil estão aquém das expectativas da Organização Mundial de Saúde - OMS (Ministério da Saúde, 2008; Venâncio, 2003; Almeida, Spiri, Juliani \& Paiva, 2008). Queiroz (2000) aponta que essas iniciativas por vezes deixam de lado os aspectos intersubjetivos da relação mãe-filho (as dificuldades relacionais, o gozo), situados além da prevenção de doenças orgânicas e da função puramente alimentar. $\mathrm{O}$ ato de amamentar ou não, a despeito da expressão no plano biológico, decorre de uma complexa rede de inter-retro-ações que precisa ser considerada no âmbito das ações em saúde voltadas ao seu incentivo.

A imposição de amamentar, e, em contraste, a dificuldade que algumas mulheres enfrentam para realizar o desmame, podem trazer conseqüências na relação mãe-bebê, alterando a qualidade da interação da díade, repercutindo no desenvolvimento psíquico infantil e no equilíbrio geral da mãe (Santos \& cols., 2001; Queiroz, 2005; Sales, 2005). Imposições e imperativos superegóicos nesses processos impedem a compreensão da história de vida da mulher e a escuta da ambivalência, deixando-se de observar os primórdios da interação mãe-bebê. Estima-se que a atitude dirigida puramente ao conhecimento crie obstáculos à atividade crítica e ao reconhecimento da articulação entre necessidade-desejo-demanda.

A metassíntese desenvolvida por Nelson (2006) aponta a complexidade do processo de "tornar-se uma mãe que amamenta", destacando que essa decisão abrange fatores objetivos relacionados ao conhecimento, além de aspectos interpessoais e subjetivos. A amamentação revelou causar impacto significativo sobre a mulher, envolvendo empenho físico e afetivo, adaptação e apoio de várias fontes, exigindo tempo na tomada de decisão e descontinuação.

Britton, Britton e Gronwaldt (2006) estudaram o aleitamento materno e o vínculo mãe-bebê, apontando que a amamentação não apresentou relação direta com o vínculo, já que o fator preditivo mais importante para um apego seguro é a qualidade da interação diádica na infância, mais do que o tipo de alimentação. Destacam que as mulheres que optaram por amamentar eram mais responsivas aos sinais de suas crianças durante o processo de interação no início da vida. A amamentação contribui indiretamente para fomentar um apego seguro, pois a sensibilidade materna está associada à intenção e duração pretendida de amamentar durante o período pré-natal, podendo ser um marcador precoce da sensibilidade posterior da mãe com relação ao bebê.

A amamentação, considerada como processo envolvendo o oferecimento de leite (por meio do seio) e o desmame (passagem do seio a outros alimentos/objetos), carrega significados que transcendem o biológico, indicando um momento singular e decisivo na constituição psíquica do bebê e bem-estar psíquico da mulher/mãe. Segundo a psicanálise, amamentar é uma das maneiras pelas quais o ser humano é convocado a ser sujeito (Queiroz, 2005; Sales, 2005; Santos \& cols., 2001; Freitas, 2005).

O leite adquire para o bebê, através das interações simbólicas com a mãe, significados singulares, situando-se entre a demanda e o desejo materno. O desmame, enquanto perda do objeto mítico de satisfação (seio materno) assume importância à díade por confrontar o bebê com perdas necessárias à conquista progressiva de laços sociais, enquanto para a mãe expressa a retomada de aspectos constitutivos da sua própria sexualidade - considerando-se as repercussões na experiência da maternidade e amamentação (Queiroz, 2005; Lacan, 1957/1995; Freud, 1931/1996).

A amamentação remete a mulher a experiências arcaicas, aos complexos e imagos familiares trans e intergeracionais que se concretizam por meio de práticas sociais, nos quais são projetados os significados individuais (Correa, 2000). A relação da mãe com o bebê depende do lugar que o filho representa em seu inconsciente: seja um objeto fálico a preencher suas faltas, ou até mesmo a ausência de desejo e investimentos afetivos. $\mathrm{O}$ modo como se estabelece a relação da mulher com o pai do bebê, e com o seu próprio pai, afeta o significado desse filho para a mãe, bem como o desempenho de funções como a amamentação e o desmame. Algumas mulheres amamentam devido à culpa que sentem em decorrência da relação conflituosa com o bebê, enquanto outras amamentam por tempo excessivo por não abrirem mão do prazer sexual propiciado pela sucção do bebê (Soler, 2003).

Segundo Sales (2005) e Laznik (2004), os efeitos psíquicos operados pela função materna e suas ações, como a amamentação, estão representados por pilares estruturantes da interação/subjetivação infantil: supor um sujeito, estabelecer a demanda da criança, alternar presença-ausência, desmame. As experiências alimentares no contexto da relação pais-filho constituem matrizes das modalidades relacionais e base para o contínuo desenvolvimento das interações infantis (Ramos \& Almeida, 2003).

A amamentação proporciona ao bebê a ilusão da continuidade intra-uterina, funcionando como pára-excitação diante das angústias do neonato, pois o fluxo morno do leite e o contato da mucosa labial com o seio desperta na criança um prazer que excede à necessidade de aplacar sua fome (Freud, 1920/1996).

Segundo Winnicott (1958/1978) a boa experiência de amamentação constitui o fundamento do desmame, de modo que este deve ser a conclusão de um trabalho de amamentação bem conduzido, indicando que a criança teria alguma coisa da qual poderia ser desmamada. Amamentação e desmame estão interligados porque é somente como objeto perdido que o seio é apreendido, e a falta do objeto é a mola da relação do sujeito com o mundo, em sua eterna busca por objetos substitutos (abandona a posição de ser o falo da mãe, para procurar tê-lo). Na identificação com a parte perdida de si mesma a criança sobrevém então como sujeito de desejo (Lacan, 1957/1995).

Considerando o desmame um organizador do desenvolvimento psíquico, Lacan (1938/1993) o concebe como um complexo que recobre psiquicamente a história da relação alimentar e de cuidados (imago materna), operando um corte real na relação biológica entre o corpo da mãe (seio) e do bebê (boca), deixando uma marca essencial na vida imaginária tanto da mãe como da criança. Esses processos psíquicos, ancorados no corpo, estão na origem da internalização e da simbolização (Winnicott, 1958/1978).

Passar para outro alimento e aceitar a intervenção paterna implica o importante jogo simbólico de substituições, interditando e transpondo o gozo oral para o gozo fálico por meio do recalque da pulsão oral. É através do processo de desmame que a mãe pode abrir mão da relação de poder e 
dependência da criança em relação a ela; do lado da criança, significa suportar a separação do corpo materno, aceitar trocas e substituições, sobretudo aceitar a convocação para o mundo da cultura (Sales, 2005).

"A amamentação é o tempo permitido à criança para permanecer nessa relação incestuosa, mas essa relação deve ser proibida a partir de um determinado momento e submetida à castração para que a criança possa justamente ter acesso ao simbólico. É pela castração que a sexualidade se torna sexual, o seio muda de estatuto, torna-se objeto erotizado, mas proibido." (Queiroz, 2000; p. 149)

A metáfora paterna é considerada condição para o desmame, operando como terceiro que permite ao bebê se afastar da relação dual e do desejo da mãe, privador tanto do filho como da mãe (Guerra \& Simões, 1995; Sales, 2005; Queiroz, 2005; Freitas, 2005). Segundo Queiroz (2005) a dificuldade em desmamar pode recobrir uma falha na metáfora paterna, não conseguindo operar o importante "não" no gozo entre mãe e filho, impossibilitando a substituição do seio e do leite materno por outros objetos (alimentos, brinquedos). Ao ignorar a singularidade do bebê, a mãe cria obstáculos à separação e autonomia necessárias à constituição subjetiva do filho. Questiona-se também o risco de distúrbios infantis quanto à alimentação, em vista da boca se transformar numa área de gozo, independente da condição nutricional do leite materno (Freitas, 2005).

Admite-se o paralelo entre o jogo de deixar cair objetos (fort-da) e o desmame, atividades que refletem a separação psíquica criança/seio/mãe (Freud, 1920/1996). Esse jogo começa aproximadamente aos cinco meses de idade e persiste até 12 ou 18 meses, período em que alguns autores acreditam que a criança estaria apta ao desmame (Winnicott, 1958/1978; Dolto, 1992).

A OMS (1999) recomenda a amamentação exclusiva até os seis meses, e o desmame por meio da manutenção do aleitamento materno, acrescido de outras fontes nutricionais, até os 24 meses ou mais. A falta de acordo entre o senso comum e o meio científico quanto à duração da amamentação e a idade ideal para o desmame deixa mães e profissionais de saúde confusos, provocando conflito pessoal, profissional e social (Hames, 2006).

Destacam-se estudos abordando a associação entre duração da amamentação e estado nutricional (Victora, Vaughan, Martines \& Barcelos, 1984; Caulfield, Bentley \& Ahmed, 1996; Fawzi \& cols., 1998). Victora e cols. (1984), acompanhando o estado nutricional de crianças amamentadas após os 12 meses de idade, observaram que os indicadores antropométricos (peso e altura) pioravam com o prolongamento da amamentação, com prevalência significativamente maior de baixo peso para a altura em comparação com crianças totalmente desmamadas.

Apesar de estudos transversais identificarem associação inversa entre amamentação prolongada e desnutrição, a análise longitudinal de Fawzi, Herrera, Nestel, Amin e Mohamed (1998) sugere que não há evidência de que a amamentação prolongada por si só esteja relacionada à desnutrição. No entanto, o mesmo estudo identificou que crianças desnutridas são amamentadas por mais tempo, estando mais propensas a receberem alimentação complementar de modo inadequado (Fawzi \& cols., 1998).
A desnutrição infantil é um processo multicausal com condicionantes biológicos, emocionais e sociais, incluído o vínculo mãe-filho (Nóbrega, 2005; Sociedade Brasileira de Pediatria, 2002). Pode ser tomada como uma situação de risco não apenas socioeconômico, pois os primeiros conflitos interacionais encontram expressão na esfera da alimentação (Cullere-Crespin, 2004; Lemes, Moraes \& Vitolo, 1997; Kreisler, 1999).

A alimentação deve, portanto, ser compreendida para além das necessidades fisiológicas (Lemes \& cols., 1997; Kreisler, 1999), situada na complexidade da interação entre necessidade do alimento e demanda de amor (Lacan, 1957/1995), envolvendo a incorporação de algo mais que alimento.

Este artigo pretende analisar a psicodinâmica envolvida no desmame precoce/desmame tardio, buscando lançar luz nas possíveis dificuldades no estabelecimento da amamentação/realização do desmame, com base em recortes de elementos da interação mãe-criança desnutrida grave hospitalizada. Questionam-se as conseqüências desses eventos ao desenvolvimento nutricional e psíquico infantil.

\section{Método}

O estudo ocorreu entre novembro de 2006 e abril de 2007, analisando elementos da psicodinâmica interativa da díade mãe-criança desnutrida grave internada em enfermaria pediátrica (Sampaio, Falbo, Camarotti \& Vasconcelos, 2007). Este artigo analisa recortes da psicodinâmica envolvida no desmame precoce e no desmame tardio, em duas díades participantes do referido estudo.

A pesquisa qualitativa apoiada na psicanálise delineou a abordagem teórico/metodológica do estudo, realizado no Instituto de Medicina Integral Prof. Fernando Figueira (IMIP), hospital escola na Região Metropolitana central do Recife, Pernambuco, Brasil, entidade não-governamental, filantrópica, sem fins lucrativos.

As crianças incluídas apresentavam desnutrição grave primária (índice peso/altura $<-3$ escore $\mathrm{z}$, segundo o padrão da OMS (1999), e/ou presença de edema simétrico envolvendo no mínimo os pés).

Foram selecionadas circunstancialmente oito díades, acompanhadas ao longo da hospitalização. A seleção dos sujeitos valorizou as diferenças dentro de um grupo homogêneo (crianças com desnutrição grave primária e mulheres com o mesmo padrão socioeconômico), porém ilustrando com riqueza as diversas nuances do processo interativo (díades com rede social vasta/precária, com dificuldade/facilidade na aquisição de alimento, dentre outros), segundo entrevista de contato inicial e com base nos dados do prontuário da criança. O término da coleta atendeu ao critério de saturação das respostas mediante reincidência e complementaridade das informações (Minayo, 2007; Fontanella, Ricas \& Turato, 2008).

Foram realizadas entrevistas individuais semi-estruturadas, observações participantes (livres e estruturadas, filmadas ou não), anotações em diário de campo e anotações retiradas do prontuário da criança, buscando-se a triangulação de instrumentos de registro e fontes de dados.

A análise buscou apreender as categorias produzidas pelos sujeitos e pesquisadores, com base no material empírico, 
abordando os processos compreensivos e inconscientes. As informações foram interpretadas de acordo com o contexto sócio-histórico e individual, levando-se em conta o fenômeno transferencial, considerado na relação intersubjetiva como essencial na compreensão do lugar ocupado pela pesquisadora e da trama psicodinâmica das relações de objeto, interações típicas dos participantes, para além do comportamento manifesto. Buscou-se a compreensão da psicodinâmica por meio da análise do lugar que a criança parecia ocupar no universo materno, bem como o lugar em que a mãe parecia colocar a pesquisadora.

A condução do fenômeno transferencial marca a diferença entre a técnica como modalidade de tratamento em psicanálise e o uso do método de investigação orientado por esta. A transferência não foi interpretada, no aspecto psicanalítico, pois o objetivo era compreender e não trabalhar o fenômeno transferencial.

A análise do material foi iniciada por leitura flutuante, seguida por exame repetido dos dossiês, buscando compreender as idéias nucleares em relação aos elementos de análise. A unidade de contexto foi a entrevista como um todo (Bardin, 1977; Minayo, 2007). Para aprofundar a compreensão dos núcleos de sentido, utilizou-se a metodologia de análise de conteúdo, associada à técnica de análise da enunciação, realizando-se recortes transversais de falas e atos de fala das díades (Bardin, 1977).

O estudo valorizou a triangulação de técnicas e instrumentos de pesquisa, da teoria e a triangulação de pesquisadores na análise do material (Gomes, Souza, Minayo, Malaquias \& Silva, 2005). As observações do diário de campo, transcrições das entrevistas e filmagens foram analisadas individual e coletivamente através de discussões entre os membros da pesquisa (uma pesquisadora de campo e três orientadores de pesquisa), tendo em vista a troca de impressões e informações. A validade interna foi almejada através do profundo engajamento ao objeto pesquisado, observações persistentes e a possibilidade de confrontar interpretações junto às mulheres envolvidas.

A pesquisa obteve a aprovação prévia do Comitê de Ética em Pesquisa em Seres Humanos do IMIP. A coleta de dados foi realizada com prévia assinatura do Termo de Consentimento Livre e Esclarecido.

\section{Resultados e Discussão}

As díades foram denominadas Rosácea (25 anos) e Angélica (seis meses), Bela (20 anos) e Ian (quinze meses). A condição socioeconômica das famílias era precária, característica compatível com o perfil da clientela do hospital estudado. Ambas não tinham acesso a auxílio social, apesar de haver solicitado. Referiram período(s) em que passaram dificuldade financeira, até fome, ao longo da sua própria infância.

As gestações não foram planejadas, porém acompanhadas em pré-natal (pelo menos três consultas). Tendo em vista a melhoria do sustento financeiro da família com a chegada do novo membro, os maridos passaram a trabalhar mais, viabilizando a aquisição do alimento. As mães descreveram-se como casadas; não trabalhavam, passando o dia com os filhos. A escolarização variou de três a oito anos de estudo.
Rosácea tinha quatro filhos. Angélica nasceu a termo, com quase quatro quilos. Apesar disso, Rosácea a descreveu como uma criança "doentinha desde o nascimento" (sic). Bela estava no terceiro relacionamento conjugal. Ian nasceu a termo, pesando cerca de três quilos e meio; era seu segundo filho, antes do qual teve um natimorto.

Ian dormia entre Bela e o marido desde que este passara, após cinco meses do nascimento da criança, a se ausentar de casa por períodos mais longos diante da rotina de trabalho. Bela relatava não suportar a ausência do marido, compensando-a com a não ruptura do corpo-a-corpo com o filho, permanecendo grande parte do dia com a criança na cama, onde o amamentava. Conteúdos como estes foram destacados por Carrascoza, Costa-Júnior, Ambrosano e Moraes (2005) sobre argumentos maternos relativos ao prolongamento da amamentação. As díades eram provenientes de outros hospitais da rede pública por insucesso no tratamento da doença. As internações duraram 28 (Angélica) e 17 dias (Ian).

As mães descreveram a amamentação como uma atividade fundamental à saúde materna e infantil, repetindo a linguagem científica. No entanto, os quatro filhos de Rosácea foram desmamados antes dos seis meses, recebendo leite em pó acrescido de massa. Bela amamentou a filha mais velha até os oito meses e desejava amamentar o bebê natimorto, narrando seu sofrimento ao acordar à noite com os seios escorrendo, sonhando que o amamentava. Ian ainda mamava quase que exclusivamente aos 15 meses, com importante dificuldade da aceitação de outros alimentos.

\section{Alimentação e psicodinâmica interativa das díades}

Angélica recebeu amamentação exclusiva por pouco mais de um mês. No entanto, Rosácea achava que a filha não engordava, passando a seguir o conselho das vizinhas de oferecer "leite em pó forte" (sic). Aos dois meses, a dieta da criança consistia de mingau (leite com massa), vitamina de banana, etc. Achou que Angélica não queria mais mamar e que seu leite fraco secara. Queiroz (2005) aponta que a recusa do bebê por vezes denuncia dificuldades maternas na amamentação ou aponta conflitos familiares inter ou transgeracionais; culpada pelo desmame precoce e sem espaço para falar de sua angústia, a mãe elege uma causa socialmente mais aceitável que o seu "fracasso".

Rosácea foi contraditória e confusa quanto ao modo de alimentação da filha, tanto em casa como no hospital, parecendo não compreender os sinais interacionais da criança. $\mathrm{O}$ alimento artificial parecia ser usado diante da desvalorização da figura materna, em detrimento do leite do peito. "É, ela nasceu magrinha, desnutridinha... (...) Meu leite tava deixando ela mais magra ainda" (Rosácea).

Lacan destaca que, embora o objeto real não seja indiferente, não há necessidade de ser específico:

Mesmo que não seja o seio da mãe, nem por isso ele perderá algo do valor de seu lugar na dialética sexual, de onde se origina a erotização da zona oral. Não é o objeto que desempenha, em seu interior, o papel essencial, mas o fato de que a atividade assumiu uma função erotizada no plano do desejo, $o$ qual se ordena na ordem simbólica (Lacan, 1957/1995, p. 188). 
Para a criança, não importa o alimento que a mãe oferece, mas a posição a partir da qual faz a oferta: a partir de seu corpo, situada apenas no eixo da necessidade, sem veicular afeto, ou oferecer um consolo (fralda, objeto) e conseguir satisfazer a criança. Dava a impressão que o leite de Rosácea era fraco não de nutrientes, mas de significado, de investimento materno, fraco de algo que está além do valor nutritivo. Talvez Angélica recusasse o leite/peito porque não vinha recheado de afeto.

Rosácea parecia tomar as manifestações da criança de modo unívoco, como demanda por comida, o choro e balbucios como fome; esse tipo de "leitura" parecia ocorrer já desde a gestação, diante dos movimentos fetais. A escuta e interpretação materna às manifestações do filho só é possível quando existe um investimento da mãe no corpo da criança, transformando um corpo de sensações em um corpo falado (Fernandes, 2005), interpretando os sinais corporais como atos de fala, trocas interativas de um sujeito-interlocutor (Ferreira, 1997).

Ao longo da hospitalização, no entanto, conseguiu criar novos significados às demandas e comportamentos de Angélica, porém nunca os comunicando à criança. Era angustiante assistir às tentativas maternas de alimentá-la. Estas evidências podem ser observadas nos registros de campo: Angélica está mal posicionada no colo da mãe, praticamente deitada, com as pernas e braços presos, enquanto Rosácea tenta achar um espacinho na boca da criança para despejar o leite. Angélica reluta, bota o leite pra fora com a língua, vira a cabeça, enquanto esta insiste, numa verdadeira luta. É angustiante observar a cena. A mãe tenta "injetar" o leite com a seringa, sequer deixando a filha chorar. A expressão de Angélica é de sofrimento. Não chama a atenção da filha para si, não a estimula com falas, risos, manhês, não faz o leite atraente.

Angélica não esboçava nenhuma reação diante da saída de Rosácea, parecendo não fazer diferença quando a mãe se afastava. Certa vez uma das mães da enfermaria comentou: "o olhar dessa bebezinha parece dizer que ela quer viver, mas não sabe como lutar”. De fato, Angélica não parecia ter prazer em comer, por isso, apesar da fome, regurgitava o leite, expulsando aquilo que deveria lhe trazer vida, dar prazer, parecendo carecer de algo mais básico que o leite: a mãe, engolir e ter prazer com essa mãe, com o corpo dela. Rosácea não parecia ter prazer em alimentar a criança.

Com duas semanas de internação, comentou que seus seios haviam inchado, chegando a derramar leite, diante do que voltou a amamentar a filha. Entretanto, o desejo de se oferecer à filha enquanto objeto de amor não parecia estar presente, de modo que Rosácea não se doava, não estabelecia uma relação de vínculo com Angélica. Questiona-se se ela amamentava Angélica, no sentido libidinal do termo; segundo Sales (2005), a mãe só amamenta o filho quando se deixa mamar pela criança. Os registros do diário de campo informam que: Rosácea não parece saber o que fazer com Angélica em seu colo. A criança reclama, coloca as mãos na cabeça, mas a mãe não consegue acolhê-la, balançando-a sem jeito. Não parece tomar a criança como interlocutora. A criança parece perdida no seu colo, inquieta, com raiva. Rosácea dá o peito de modo estranho, não colocando a filha em seu corpo, apenas encaixando a boca no seio, meio que mirando a boca da criança. Dá certo, Angélica pára de es- pernear, de reclamar, mas não se aninha ao corpo da mãe. Amamenta a criança sem dizer nada, segurando o bracinho dela, não a deixando explorar seu corpo. Não há troca de olhares. Quando Rosácea tem algo a comentar quanto às reações da filha, sempre se dirige a mim, nunca à criança.

Associando o volume abdominal ao aumento de peso, bem como o ganho médio de peso (GMP) à alta, passou a superinvestir na alimentação da filha. Observando importante edema, a equipe solicitou auxílio do Serviço Social, ameaçando Rosácea. Diante do medo de perder a filha para a lei ou para a morte, temendo deixá-la com fome ou sede, "entupia" a criança com leite do peito. Poucos dias depois Angélica morreu em função de uma parada cardiorrespiratória associada ao excesso de líquido ofertado. Os registros indicam que: A nutricionista disse que haviam suspendido o peito porque Angélica estava mais edemaciada. No entanto, Rosácea achou que o leite da sonda não era suficiente e que a criança estava com fome. Acabou dando o peito diversas vezes, aumentando o edema, o que talvez tenha contribuído para a parada cardíaca. Tentando levar a criança com vida para casa e confortá-la diante da suposta fome, "entupiu-a" de leite. Ao final, foi o leite que influenciou, de uma forma ou de outra, a morte da criança. Morreu, paradoxalmente, por excesso de comida, mesmo desnutrida.

A alimentação de Ian consistia basicamente do leite materno, apesar da introdução de consistências e sabores diversos. Bela reconhecia que a criança "comia de tudo", mas depois sempre pedia peito, ao que não era negado. Os registros indicam que: De cinco em cinco minutos era peito. Sempre que eu dava comida, quando ele acabava de comer eu dava o peito. Sempre tive vontade, nunca tirar ele do peito não (Bela).

O leite materno parecia ser usado diante da suposta recusa da criança em comer outros alimentos, a mãe aparentemente reforçando a dependência do filho no peito, com pode ser notado nos registros: Comigo ele num come, que é a mania dele no peito! Ele sabe que sou eu, ai se ele num comer eu vou dar o peito a ele. Aí ele já sabe e num quer comer. Com qualquer pessoa que der a comida ele come, mas comigo ele não come (Bela).

A amamentação parecia ser reforçada por Bela talvez projetando em Ian experiências trans e intergeracionais, como o medo da doença ou da fome e o receio de perder mais um filho diante da falta de comida: Quando ele ficar doente, como agora mesmo, ele ta meio adoentado, só quis peito, né?! Não come nada! Aí eu dou o peito a ele. E se eu tirasse ele do peito, ele ia ficar como, ia ser pior ainda, né?! Porque também os meus irmãozinho quando tem uma dor de cabeça, febre, uma coisa ou outra, ficava sem comer, dava o peito, ai pronto. Eu nunca vou deixar de dar o peito a ele. Vou deixar ele mamar até quando ele num quiser mais. Num vou deixar de dar não (Bela).

No início da internação queixava-se que o filho provocava vômitos, rejeitando os alimentos, solicitando e aceitando apenas ser alimentado ao peito. Apenas um episódio de vômito foi observado, já próximo da alta de Ian, quando Bela "entupiu" a criança de comida, complementando com o peito, de modo que ele ganhasse logo o peso necessário para a alta hospitalar. Pontua-se que Bela não tinha dificuldade em compreender e responder aos sinais de fome e saciedade da 
criança, mas na ocasião forçou o filho a comer por almejar o aumento de peso.

A interação entre mãe e filho transcorria sempre com muitas trocas de olhares, vocalizações, diálogos vocais ou gestuais. Bela colocava-se como tradutora, narrando as descobertas e explorações do filho. Ian tinha dificuldade em ficar só e iniciar uma brincadeira; a mãe e seu peito pareciam ser seus brinquedos prediletos.

No início da internação Bela também tinha dificuldade em se afastar do filho, temendo que ele fosse "roubado" (sic), chegando a perder peso por não ir ao refeitório. Desejava inclusive dar de mamar cada vez mais, pois a norma do hospital era que as mães que amamentavam recebiam sua própria dieta na enfermaria. Parecia reviver experiências como a separação/perda da filha para a ex-sogra, e a perda (morte) do bebê no final da gestação. Toda vez que Bela se ausentava da enfermaria por um período mais longo Ian chorava incessantemente, preenchendo a falta da mãe com seu próprio choro, recusando-se a aceitar outras fontes para aplacar sua angústia.

Quando Bela ia alimentar Ian a atividade geralmente se passava com muita dificuldade, pois ele freqüentemente pedia o peito e ela não conseguia dizer "não" ao filho, cedendo, por vezes até deixando de dar a dieta.

Bela passou a reconhecer que a dificuldade de Ian para comer também estava ligada à sua própria dificuldade em colocar limites na criança. Faltava um terceiro nessa relação, ao que a equipe de saúde por vezes mostrava-se desejosa em ocupar esse papel. Os registros indicam que: Bela dá a comida a Ian, mas ele passa a pedir o peito, puxando a blusa da mãe com voracidade. Ela se recusa a dar o peito e ele se irrita. Bela não consegue dizer "não" com firmeza, beijando Ian e dizendo que o peito está "dodói”. Ele insiste, ela então diz que se ele comer dará o peito. Ian chora, Bela aproveita e empurra uma colher de comida, ao que ele quase se engasga. Ela se diverte com a barganha que ofereceu (o resto da comida por peito), mas Ian se irrita ainda mais, insistindo no peito, puxando a blusa da mãe. Bela acaba cedendo. É Ian quem controla a atividade. Enquanto dá de mamar, comenta "tem que comer pra ficar forte pra sair daqui, viu?!”. Troca intensa de carinhos e olhares enquanto amamenta, ao que Bela demonstra muito prazer. Depois de um tempo dá um pouquinho de comida, junto com o peito: "por favorzinho, neném, só esse pouquinho e mainha dá o teito". Por fim, dá o peito por vontade própria, pois a criança já não pedia mais.

Em certos momentos, a criança parecia ocupar o lugar de brinquedo erótico para Bela; o risco era Ian ocupar esse lugar. Por vezes mãe e filho pareciam brincar e brigar ao mesmo tempo, geralmente durante as mamadas, quando Ian praticamente arrancava a blusa da mãe para mamar ou quando mordia o seio de Bela. Lacan (1957/1995) destaca que uma criança com dentes é uma criança sexuada (phallus dentatus). De quem era a dificuldade em efetivar o desmame?

Confrontada pela equipe com a perda de peso do filho, ciente da necessidade de alimentá-lo, bem como visando o GMP, Bela passou a solicitar que a avó paterna de Ian permanecesse no hospital nos horários da dieta. Seu medo de repetição da experiência de "perda" de um filho para a ex-sogra parecia ser vivido de modo ambivalente: ora prati- camente oferecia a criança à sogra, se divertindo ao ameaçar entregar Ian à avó, ora reforçava a alimentação ao seio. Ian, em contrapartida, chamava indistintamente mãe e avó de "bó-bó": E se ele continuar nessa dificuldade pra comer, se só quiser o peito? Eu vou dar só o peito! Vou fazer o quê, se ele vai querer só o peito?! Mas eu vou tentar muito, vou passar assim tempo sem dar o peito a ele, pra ver se ele come, vou deixar uns tempo ele na casa da minha sogra pra ver se ele come. Ai toda hora, toda vez que marcar a hora dele comer ai eu vou dou a ela pra ele comer. Depois quando ele parar de comer eu vou e pego ele de volta (Bela).

Diante da dificuldade da sogra em permanecer no hospital, das frequentes pontuações da equipe e inconstância do GMP, Bela passou a oferecer mais o alimento do hospital que o peito. Conseguiu também se afastar mais do filho, ao que este passou gradualmente a aceitar a saída da mãe, engajando-se em brincadeiras de deixar cair objetos e "esconde-esconde", numa espécie de fort-da. Apesar de ter brinquedos em casa, foi no hospital que Ian passou a "brincar com brinquedos", segundo Bela.

Bela pôde, aos poucos, separar-se de Ian, deixando que ele olhasse o mundo além do seio materno, sem temer perder a criança ou "dá-la" para outras "sogras", assim como pôde ressignificar a fome, suportando a "fome" do filho: Quando eu saio pra comer ele fica chorando. Antes eu ficava com fome, fraca, sem poder comer. Agora aprendi: deixei ele com fome e agora ele come a comida e não pede mais tanto o peito (Bela).

Quinze dias após a alta, a díade retornou ao hospital para consulta com a pediatra e a nutricionista. Ian perdera peso; Bela ainda enfrentava dificuldades para alimentar o filho e conciliar as mamadas, deixando-o com outrem para que comesse. Ian permaneceu colado ao seio materno apesar das inúmeras e frequentes orientações da equipe de saúde; Bela relatou que não faltava comida em sua casa (recebera uma farta cesta por ocasião da alta hospitalar). Destaca-se que infelizmente a díade não foi encaminhada ao ambulatório de psicologia. No que concerne à comunicação equipe de saúde-mãe, Feliciano e Kovacs (2003) sugerem a superação de modelos paternalistas e informativos, visando uma comunicação bidirecional, assumindo posição crítica na busca por uma nova prática clínica.

Admitindo-se amamentação e desmame como jogos de querer/poder, oferecer/receber, acolher/abrir mão da dependência, Bela não abria mão do poder sobre o filho, diante da ameaça de solidão, fome e doença. Rosácea, em contraste, não se colocava como detentora do poder de acolher, pontuando-se que a criança precisa, nos cuidados, sentir-se objeto de satisfação para um outro que se mostra desejante.

Em Bela e Ian, o alimento precisava ser colocado na relação para que a falta materna pudesse existir, ao passo que Rosácea sequer parecia existir para Angélica, e vice-versa, de modo que não existia lugar para o alimento e o alimentar.

$\mathrm{O}$ discurso da equipe relativo à importância da amamentação e introdução do desmame era reproduzido pelas mães talvez com o intuito de alcançar a alta hospitalar, diante do que a equipe esperava ouvir delas. Estima-se que a dificuldade de Bela quanto ao desmame não dizia respeito à falta de informação, pois sabia que a amamentação exclusiva a uma criança de oito meses não era nutricionalmente suficiente, 
podendo levar à desnutrição, como ocorrido à primeira filha. No entanto, não reconhecia que isso pudesse ocasionar desnutrição em Ian, de um ano e três meses: Foi muito duro deixar ela lá... (entregar a filha mais velha à ex-sogra) Foi porque ou ela, ou eu bem comia, porque nesse tempo a gente num tinha nem cumê pra gente, como eu ia alimentar ela? $O$ peito já com oito meses de idade, num dava nada, né, porque mijou, pronto, foi embora.

Para ambas as mães, a alimentação era uma atividade tomada na maioria das vezes apenas em seu sentido funcional (ganho de peso), reforçado pela equipe de saúde e tomado por elas como único ou principal meio para saúde/alta hospitalar. Era frequente o uso do alimento como resposta ao desconforto do filho pelo fato da mãe não conseguir dizer "não" à criança ou não conseguir acalmá-la com outros recursos, onde o alimento/peito parecia deslocado de sua função nutritícia: Se ele ta com fome? Ta nada! Toda vez que eu der o leite a ele tem que ter peito. Eu num sei, acho que já é mania, já é costume. Ele chorando, vou fazer o quê se ele vai querer só o peito?! (Bela).

O oferecimento do alimento como resposta imediata a qualquer desconforto foi mencionado por Almeida (1993) como indicador de vulnerabilidade frente a problemas de alimentação infantil. Diante da orientação de se oferecer o leite materno sob livre demanda, bem como frente a qualquer manifestação de desconforto da criança, Sales (2005) atenta para o risco de se promover a fusão entre peito e leite, onde o peito se transforma numa fonte de leite, deserotizada, mecânica, e para a criança, como único objeto não só para satisfazer sua fome, mas também para fazer calar e sedar.

No que concerne ao interjogo demanda-desejo, foram observados tanto hipofuncionamento diádico (Rosácea e Angélica), como hiperfuncionamento (Bela e Ian). Esses quadros refletem, segundo Rohenkohl (2001) a perseguição materna na realização do seu desejo, sem se dar conta das necessidades do filho (hiperfuncionamento), ou a pobre demanda libidinal materna frente à criança (hipofuncionamento).

No hipofuncionamento, o grito da criança não parece ecoar na mãe, caindo no vazio, é secundariamente a esta ausência de resposta continente que a passividade se instala (Cullere-Crespin, 2004). A criança passa a se apresentar aparentemente tranquila, porém apática, hipotônica e hipersônica, com retardo no desenvolvimento, atraso de peso e altura, comumente acompanhado de depressão, o que tende a gerar erros de diagnóstico (Cullere-Crespin, 2004; Kreisler, 1999).

Semelhante ao que Kreisler (1999) referiu como "anorexia primária ou de inércia", Lacan (1957/1995) conceituou "anorexia mental", estado onde o que impera não é relativo ao não comer, mas ao comer nada, no plano simbólico, deixando evidente a diferença entre necessidade e desejo. A criança come "nada" para guardar vazio o espaço do desejo, de modo a não ser tomado pela necessidade do alimento (Lacan, 1957/1995). O "preenchimento passivo", sem apetite nem prazer aponta a indiferenciação do laço: não importa quando nem quem (Cullere-Crespin, 2004).

Diante do quadro alimentar de Angélica, mãe e equipe se engajavam em "salvá-la", satisfazê-la com a oferta de objetos reais (peito, leite, brinquedos), tomando a falta/inapetência/ pobreza/desnutrição como um vazio a ser preenchido no real, não tomando a falta e a própria desnutrição, em seu sentido simbólico, como motor do funcionamento psíquico da criança. A satisfação afetiva é tão central que sua ausência pode entravar a própria necessidade alimentar; a reintrodução sozinha do alimento não foi suficiente para "salvar" Angélica.

Os pais dessas crianças pareciam excluídos ou se excluíram da função paterna; sozinha em sua relação com o filho, a mãe pode passar a exercer sua função de modo omisso ou, pelo contrário, excessivo, contrastando com a incapacidade/ fraqueza da vertente paterna (Cullere-Crespin, 2004). Para Rosácea, a função paterna se associava basicamente ao provimento; o adoecimento de Angélica foi relacionado, dentre outros aspectos, à dificuldade financeira do marido em adquirir leite. No caso de Bela, por motivos financeiros, o marido precisava se ausentar, parecendo se afastar também imaginária e simbolicamente. A mãe associou o adoecimento de Ian à diminuição da atenção dispensada pelo marido após o início do emprego, ocorrido na época esperada para a introdução do desmame. Chama-se atenção para a ausência do marido/pai e sua repercussão à díade num momento essencial à entrada de um terceiro, principalmente se outra figura não puder assumir a função paterna.

Em Bela e Ian a função materna parecia "transbordada"; a criança respondia ao desejo materno, buscando fisgar a mãe através dos supostos vômitos, recusando a dieta, "colando-se" ao seio, seu objeto primordial e favorito, quase que exclusivo. Preso à satisfação materna, se satisfazia em ser aquele que satisfaz a mãe. Bela reforçava o movimento do filho de satisfazê-la continuamente através da constante busca de Ian por seu seio, assumindo a qualidade de "boa mãe", aquela que dá o peito a qualquer hora diante da demanda da criança. Fazia o que fora impedida de fazer com os outros filhos.

Sales (2005) observa que a restrição dos objetos pode levar a um empobrecimento do auto-erotismo, atingindo a capacidade da criança de estar só e sem angústia na ausência materna. A ligação excessiva ao real do corpo materno, vivida de forma erótica, pode interferir na organização sexual da criança.

Bela reconhecia a dificuldade em colocar limites no filho, atestando a falta de atenção do marido/pai. Supõe-se que o hospital tenha sido tomado por Bela como representante da função paterna, mostrando-lhe que ela mesma e Ian podiam ficar separados, a criança podia ficar só quando ela saía para almoçar (presença-ausência), era capaz de "brincar com brinquedos" e de comer outras comidas, desde que a mãe dissesse "não" ao desejo de mamada (dela e do filho). Desse modo, o adoecimento e a hospitalização pareceram, até certo ponto, figurar experiências potenciais no resgate e proteção clínico-nutricional e funcional (funcionamento materno e filial).

\section{Considerações finais}

O prolongamento da amamentação assim como o desmame precoce são influenciados por inúmeros aspectos, tais como os biológicos, histórico-culturais, econômico-sociais e psíquicos dos atores direta e indiretamente envolvidos, reconhecendo-se um processo impregnado de ideologias e determinantes que resultam das condições inconscientes e concretas de vida. O processo da amamentação está ligado às leis do inconsciente, especialmente ao desejo do Outro 
e à posição dos sujeitos envolvidos em relação à cadeia significante.

Neste estudo, o desmame precoce pareceu associado à dificuldade na construção da maternidade e vínculo; o desmame tardio refletiu o excesso psicoafetivo materno/ dificuldade na entrada do terceiro. A alimentação, incluindo a amamentação e o desmame, é um momento privilegiado para a interação mãe-criança e fundamental para o processo de subjetivação, propiciando ações simbólicas estruturantes, com importantes efeitos no psiquismo materno e infantil.

É fundamental refletir sobre a responsabilidade atribuída à mãe quanto à sobrevivência do bebê por meio da amamentação, considerando as dificuldades e limites associados à subjetividade da mulher. Propõe-se ampliar a escuta sobre a tríade mãe-pai-bebê, considerando os aspectos constitutivos da sexualidade da mulher, o vínculo mãe-bebê e a entrada do pai nessa relação, tendo em vista a prevenção de distúrbios psíquicos, visando uma amamentação e desmame de boa qualidade.

A equipe de saúde tem papel preventivo no sentido de favorecer a amamentação e respeitar a relação imediata entre mãe e bebê, e, ao mesmo tempo, ocupar o lugar de interdição (Queiroz, 2005). Deve-se intervir diante do excesso ou da falta materna/paterna, sobretudo se a mãe/pai não se dá conta disso (Laznik, 2004).

O recorte dos dados ilustrou o encontro possível entre pediatria e psicanálise. Propõe-se aprofundar o debate transdisciplinar que permeia a temática da alimentação, partindo-se do reconhecimento do inconsciente e do gozo na relação mãe-filho, tendo em vista a ampliação dos cuidados integrais em saúde.

\section{Referências}

Almeida, M. M. (1993). A clinical study of early feeding difficulties: risk and resilience in early mismatches within parent-infant relationship. Dissertação de Mestrado, Tavistock Clinic and University of East London, London.

Almeida, J. A. G., \& Novak, F. R. (2004). Amamentação: um híbrido natureza-cultura. Jornal de Pediatria, 80, 119-125.

Almeida, G. G., Spiri, W. C., Juliani, C. M. C. M., \& Paiva, B. S. R. (2008). Proteção, promoção e apoio ao aleitamento materno em um hospital universitário. Ciência \& Saúde Coletiva, 13, 487-494.

Bardin, L. (1977). Análise de conteúdo. Lisboa: Edições 70.

Britton, J. R., Britton, H. L., \& Gronwaldt, V. (2006). Breastfeeding, sensitivity, and attachment. Pediatrics, 118, 1436-1443.

Carrascoza, K. C., Costa Junior, A. L., Ambrosano, G. M. B., \& Moraes, A. B. A. (2005). Prolongamento da amamentação após o primeiro ano de vida: argumentos das mães. Psicologia: Teoria e Pesquisa, 21, 271-277.

Carrascoza, K. C., Costa Junior, A. L., \& Moraes, A. B. A. (2005). Fatores que influenciam o desmame precoce e a extensão do aleitamento materno. Estudos de Psicologia, 22, 433-440.

Caulfield, L. E., Bentley, M. E., \& Ahmed, S. (1996) Is prolonged breastfeeding associated with malnutrition? Evidence from nineteen demographic and health surveys. International Journal of Epidemiology, 25, 693-703.
Chaves, R. G., Lamounier, J. A., \& César, C. C. (2007). Fatores associados com a duração do aleitamento materno. Jornal de Pediatria, 83, 241-246.

Correa, O. B. R. (2000). O legado familiar: a tecelagem grupal da transmissão psíquica. Rio de Janeiro: Contra Capa Livraria.

Cullere-Crespin, G. (2004). A clínica precoce: o nascimento do humano. São Paulo: Casa do Psicólogo.

Dolto, F. (1992). A imagem inconsciente do corpo (N. Kon \& M. Levy, Trad.). São Paulo: Perspectiva. (Trabalho original publicado em 1984).

Faleiros, F. T. V., Trezza, E. M. C., \& Carandina, L. (2006). Aleitamento materno: fatores de influência na sua decisão e duração. Revista de Nutrição, 19, 623-630.

Fawzi, W. W., Herrera, M. G., Nestel, P., Amin, A. E., \& Mohamed, K. A. (1998). A longitudinal study of prolonged breastfeeding in relation to child undernutrition. International Journal of Epidemiology, 27, 255-260.

Feliciano, K. V. O., \& Kovacs, M. H. (2003). As necessidades comunicacionais das práticas educativas na prevenção da transmissão materno-fetal do HIV. Revista Brasileira de Saúde Materno Infantil, 3, 393-400.

Fernandes, M. H. (2005). Corpo. São Paulo: Casa do Psicólogo, $2^{\mathrm{a}}$ edição.

Ferreira, S. M. S. O. (1997). A interação mãe-bebê: primeiros passos. Em D. B. Wanderley (Org). Palavras em torno do berço (pp. 77-88). Salvador: Ágalma.

Fontanella, B. J. B., Ricas J., \& Turato, E. R. (2008). Amostragem por saturação em pesquisas qualitativas em saúde: contribuições teóricas. Cadernos de Saúde Pública, 24, 17-27.

Freitas, L. C. C. (2005). O papel da amamentação na relação mãebebê no processo do desmame. Em L. Sales (Org.). Pra que essa boca tão grande? Questões acerca da oralidade (pp. 133-143). Salvador: Ágalma.

Freud, S. (1996). Além do princípio do prazer. Em Obras psicológicas completas de Sigmund Freud: Edição Standard Brasileira (J. Salomão \& M. Oiticica, Trad.). Rio de Janeiro: Imago, Vol. XVIII. (Trabalho original publicado em 1920).

Freud, S. (1996). Sexualidade feminina. Em Obras psicológicas completas de Sigmund Freud: Edição Standard Brasileira (J. Salomão \& Abreu J. O. A., Trad.). Rio de Janeiro: Imago, Vol. XXI. (Trabalho original publicado em 1931).

Gomes, R., Souza, E. R., Minayo, M. C. S., Malaquias, J. V., \& Silva, C. F. R. (2005). Organização, processamento, análise e interpretação de dados: o desafio da triangulação. Em M. C. S. Minayo, S. G. Assis, \& E. R. Souza (Orgs.). Avaliação por triangulação de métodos (pp. 185-221). Rio de Janeiro: FIOCRUZ.

Guerra, A. G., \& Simões, P. (1995). Dialética da falta: da incompletude à transcendência. São Paulo: Escuta.

Hames, M. L. C. (2006). Amarras da liberdade: representações maternas do processo de amamentação-desmame de crianças com idade superior a dois anos. Tese de Doutorado, Universidade Federal de Santa Catarina, Florianópolis.

Kreisler, L. (1999). A nova criança da desordem psicossomática (C. Berliner, Trad.). São Paulo: Casa do Psicólogo.

Lacan, J. (1993). Os complexos familiares (J. Gerbase \& A. Q. Andrade, Trad.). Rio de Janeiro: Jorge Zahar Editor. (Trabalho original publicado em 1938). 
Lacan, J. (1995). O seminário. Livro IV. A relação de objeto (D. D. Estrada, Trad.). Rio de Janeiro: Jorge Zahar Editor. (Trabalho original publicado em 1957).

Laznik, M.C. (2004). A voz da sereia: o autismo e os impasses na constituição do sujeito. Salvador: Ágalma.

Lemes, S. O., Moraes, D. E. B., \& Vítolo, M. R. (1997). Bases psicossomáticas dos distúrbios nutricionais na infância. Revista de Nutrição, 10, 37-44.

Li, R., Fein, S. B., Chen, J., \& Grummer-Strawn, L. M. (2008). Why mothers stop breastfeeding: mothers' self-reported reasons for stopping during the first year. Pediatrics, 122, S69-S76.

Minayo, M. C. S. (2007). O desafio do conhecimento (10 edição). São Paulo: Hucitec.

Ministério da Saúde (2008). Pesquisa Nacional de Demografia e Saúde da Criança e da Mulher - PNDS 2006. Brasília: Governo Brasileiro.

Nelson, A. M. (2006). A Metasynthesis of Qualitative Breastfeeding Studies. Journal of Midwifery \& Women's Health, 51, 13-20.

Nóbrega, F. J. (2005). Vinculo mãe/filho. Rio de Janeiro: Revinter.

O'brien, M., Buikstra, E., \& Hegney, D. (2008). The influence of psychological factors on breastfeeding duration. Journal of Advanced Nursing, 63, 397-408.

Organização Mundial da Saúde (1999). Manejo da desnutrição grave: um manual para profissionais de saúde de nivel superior e suas equipes de auxiliares. Brasília: Autor.

Queiroz, T. C. N. (2000). Amamentação e desmame. Em C. M. F Rohenkohl. (Org.). A clínica com o bebê (pp. 141-156). São Paulo: Casa do Psicólogo.

Queiroz, T. C. N. (2005). Do desmame ao sujeito. São Paulo: Casa do Psicólogo.

Ramos, C. V., \& Almeida, J. A. G. (2003). Alegações maternas para o desmame: estudo qualitativo. Jornal de Pediatria, 79, 385-390.

Rohenkohl, C. M. F. (2001). É possível formalizar os sinais patológicos na clínica com bebê? Anais do II Encontro Latinoamericano dos Estados Gerais da Psicanálise, Instituto Sedes Sapientiae, São Paulo.

Sales, L. M. (2005). Preocupações acerca dos efeitos psíquicos do aleitamento materno exclusivo sobre a função materna e sobre o bebê. Em L. Sales (Org.). Pra que essa boca tão grande? Questões acerca da oralidade (pp. 115-132). Salvador: Ágalma.
Sampaio, M. A., Falbo, A. R., Camarotti, M. C., \& Vasconcelos, M. G. L. (2007). Resultados preliminares de um estudo qualitativo sobre a interação entre mãe e criança desnutrida grave, no contexto da hospitalização. Revista Brasileira de Saúde Materno Infantil, 7, 29-35.

Santos, A., Sampaio J., Toscano, M. E., Lima, A. M. C., Amorim, M. S., \& Leal, T. M. (2001). Amamentação obrigatória? Escutando mães e pediatras. Em M. C. Camarotti (Org.). Atendimento ao bebê: uma abordagem interdisciplinar (pp. 59-68). São Paulo: Casa do Psicólogo.

Sociedade Brasileira de Pediatria (2002). Temas de nutrição em pediatria (Fascículo 02). São Paulo: Autor.

Soler, C. (2003). O que Lacan dizia das mulheres. Rio de Janeiro: Jorge Zahar Editor.

Toma, T. S., \& Rea, M. F. (2008). Benefícios da amamentação para a saúde da mulher e da criança: um ensaio sobre as evidências. Cadernos de Saúde Pública,2, 235-246.

Vasconcelos, M. G. L., Lira P. I. C., \& Lima, M. C. (2006). Duração e fatores associados ao aleitamento materno em crianças menores de 24 meses de idade no estado de Pernambuco. Revista Brasileira de Saúde Materno Infantil, 6, 99-105.

Venâncio, S. I. (2003). Amamentação: repensando as dificuldades. Jornal de Pediatria, 79, 563-565.

Victora, C. G., Vaughan, J. P., Martines, J. C., \& Barcelos, L. B. (1984). Is prolonged breast-feeding associated with malnutrition? American Journal of Clinical Nutrition, 39, 307-314.

Winnicott, D. (1978). Textos selecionados da pediatria à psicanálise (J. Russo, Trad.). Rio de Janeiro: Francisco Alves. (Trabalho original publicado em 1958).
Recebido em 09.10.08

Primeira decisão editorial em 28.09.09

Versão final em 11.11.09

Aceito em 14.10.10 